\title{
Influence of Spin Finish on Degradation, Functionalization and Long-term Storage of Polyethylene Terephthalate Fabrics Dedicated to Ligament Prostheses
}

\section{Tuan Ngoc Nguyen}

Universite Paris 13 Institut Galilee

\section{Andre Rangel}

Universite Paris 13 Institut Galilee

\section{David W. Grainger}

University of Utah College of Pharmacy

Véronique Migonney ( $\nabla$ veronique.migonney@sorbonne-paris-nord.fr )

Chemistry, Structures and Properties of Biomaterials and Therapeutic Agents Laboratory, CSPBAT- UMR CNRS 7244, Université Sorbonne Paris Nord, France

\section{Research}

Keywords: fibers, fabrics, long-term storage, polyester, medical implants, medical devices

Posted Date: September 4th, 2020

DOI: https://doi.org/10.21203/rs.3.rs-57996/v1

License: (c) (1) This work is licensed under a Creative Commons Attribution 4.0 International License.

Read Full License 


\section{Abstract}

Spin finish oil applied to poly(ethylene terephthalate) (PET) fibers is shown to alter the surface properties of commercial PET fibers in storage over extended storage times. Oil removal by solvent extraction as required for their applications is shown to be changed; fiber surface chemistry, particularly surface functionalization with anionic polymer grafts, is altered, and surface mechanical properties are altered. Spin finish oxidation in storage is proposed to produce these fiber changes in storage important to their biomedical performance.

Background: Poly(ethylene terephthalate) (PET) fabrics surface-functionalized using anionic polymer grafts to enhance their biocompatibility, cell adhesion, proliferation and functional performance as PET ligament prostheses have been developed for medical application in vascular and ligament prostheses. Here, we provide new evidence for deleterious effects of uncontrolled storage times and conditions on the final properties of PET medical fabrics and devices, specifically alteration and degradation of applied spin finish oil and fabric fiber surface properties, and limits to surface functionalization of PET fibers important to for medical uses.

Results: Textile spin finish oil effects from 2- to 25-year storage times on PET fiber degradation and surface functionalization with anionic polymers were analyzed using FTIR, DSC and by quantitative AFM nano-mechanical profiling. Degradation of the spin-finish oil/fiber interface reduced oil Soxhlet extraction efficiency due to oil solubility changes in diethyl ether or n-hexane extraction solvents. However, solvent tetrahydrofuran was shown to be the most efficient extraction solvent even after long fabric storage times, facilitating further efficient surface functionalization of PET fabrics. Surface mechanical properties of PET fibers and fabrics over storage times spanning 2 to 25 years were investigated by using AFMPeakforce QNM. Results showed significant and dramatic reduction of the surface elastic modulus of degraded PET fiber surfaces, with surface stiffness decreasing from 2.3 GPa for optimal (2-year) conditions of storage (PET 2018) to 50-85 MPa for extended storage (to 25 year) periods ( $\mathrm{PET}_{2009}$ and $\left.\mathrm{PET}_{1993}\right)$.

Conclusion: The ambient aging of textile spin finish oil with PET surfaces was shown to induce PET surface degradation, limiting oil removal, limiting further PET fiber surface graft functionalization, and compromising mechanical properties. Moreover, residual degraded finishing oils likely contained oxidation products from extended storage that alter PET fabrics.

\section{Background}

Medical grade polyethylene terephthalate (polyester, PET) yarns and fibers used for diverse medical applications, including vascular and ligament prosthetic grafts, are distinct in several aspects from PET used for other non-medical textile applications. Notably, PET strength and fiber structures are deliberately altered for implantable medical applications to produce high strength, high modulus and low elongation materials as devices. Polymer technology, textile and spinning techniques, drawing methods and 
processing machinery have been critical to enabling new PET fiber and fabric processing that yield fibers with these requisite properties [1-3].

Given current broad use of PET fibers and fabrics for medical devices applications [4], the PET ligament prosthesis holds a unique place. Despite clinical prominence of PET woven vascular prostheses for many years, recognized as the most reliable solution for replacing diseased vessels [5], PET ligament prostheses are more recently introduced and clinically important [6]. Ligament tears are increasingly common injuries in pivot sports, requiring stabilization of the knee by surgical ligament reconstruction to prevent osteoarthritis. Basically, these prostheses facilitate tissue re-connection of the torn injured ligament component, involving reconstruction of new ligament through host cellular re-attachment and healing $[7,8]$. This requires extended rehabilitation time. Nonetheless, textile ligament prostheses use remains limited due to poor control of in vivo degradation risk factors of implanted prostheses and performance that is sub-standard versus clinical standards of care. Improved ligament prostheses designs are sought.

After disastrous clinical results for the first generation of artificial ligaments, largely based on PET textile biomaterials [6], second- and third- generation PET ligament prostheses have yielded improvements in both materials and implant designs. Second-generation PET implants, developed by LARS laboratories (France), focused on a biomaterial prosthesis structure mimicking that of the natural ligament [9]. Third generation designs exploited further surface functionalizing of the PET ligament prosthesis with grafted bioactive polymers to improve biocompatibility and tissue "bio-integration", i.e. increased host cell adhesion, proliferation and signaling to stabilize implant integration [10, 11]. Migonney et al. showed that poly(sodium 4-styrene sulfonate) (PNaSS) grafting onto PET surfaces improves both adhesion and functions of fibroblast cells that constitute ligament and tendon endogenous cells [10-14].

PET ligament prostheses comprise complex knitted and woven fabrics made from commercial PET fibers previously coated with an added manufacturing oil by design [7]. The process called "spin-finish" is performed using FDA-approved synthetic or natural oil for biomedical applications [15]. Indeed, spin finish oil is coated to protect fibers, reduce fiber and fabric adhesion and stickiness, improve handling and assembly, and provide optimal properties that enable extrusion of precision calibrated PET fiber dimensions. It is well-recognized that fiber spin finish oil allows PET fabrics to be easily woven, handled and safely stored $[15,16]$. Spin finish treatments of fibers dedicated to medical devices use oils such as soybean oil containing fatty acids ester and epoxide groups for antioxidant properties [17-21]. However, depending on storage conditions (i.e. short or long term, ambient or controlled atmosphere, and strictly controlled or uncontrolled temperature), these spin finishing (or "sizing") oils either remain inert or degrade, generating oxidized species and radicals that can affect polymer fiber integrity and impede their further functionalization and properties. Prior to surface functionalization of polymers fibers or fabrics, a surface pre-treatment called spin finish removal (SFR) is usually performed using Soxhlet solvent extraction to remove the protective spin finish oil [22]. SFR is required for PNaSS "grafting from" reactions on clean PET fiber surfaces through radical grafting polymerization processes [10-14]. 
Rahman and East reported spin finish effects on the hydrolysis of medical-grade PET fibers used to produce antithrombotic fabric vascular grafts [22]. They demonstrated that spin-finish oil reduced PET degradation by ambient oxidation and hydrolysis. However, no reports describe any effect of finish oil and storage on SFR pre-treatment of PET for surface functionalization.

This study was designed to determine the influence of spin-finish treatment and long-term storage on PET fabric degradation and functionalization required for production of PET ligament prostheses. SFR was first achieved using diethyl ether (DE) as solvent for oil extraction in a Soxhlet system. Further experiments compared the extraction efficiencies of other solvents (DE vs. n-hexane, and tetrahydrofuran, THF) and the spin finish oil and resulting PET fiber alterations. After these assays, PET fabric functionalization was assessed following PNaSS radical "grafting from" polymer coating techniques in order to evaluate the efficiency and effects of the SFR process on polymer surface grafting. Results demonstrate that spin finish oil instability over time and extended storage conditions alters both SFR, surface functionalization and PET fiber/fabric degradation under long-term storage. A mechanism is proposed that correlates the significant and deleterious interactions between spin finish oil and PET fabric interfaces during storage, degrading PET surfaces and reducing PNaSS GR after SFR and grafting functionalization processing.

\section{Materials}

Polyethylene terephthalate (PET) fabrics comprising knitted and woven fibers of $25 \mu \mathrm{m}$ diameter were kindly provided by LARS (Paris, France) and stored at $20^{\circ} \mathrm{C}$ under ambient atmosphere for different times: 25 years $\left(\mathrm{PET}_{1993}\right), 10$ years $\left(\mathrm{PET}_{2009}\right)$, and 1 year (PET 2018). Diethyl ether (DE) (Fisher), n-hexane (Fisher), and tetrahydrofuran (THF, Fisher) were used as extraction solvents. PET film (reference for DSC control, semi-crystalline PET film) was purchased from Goodfellow (Paris, France).

\subsection{Fabric preparation}

PET fabrics were cut into small pieces $(3 \times 3 \mathrm{~cm}, 35-40 \mathrm{mg})$. These samples were (i) DE washed by Soxhlet extraction to achieve the SFR process, (ii) quickly dried by DE evaporation, (iii) rinsed in ethanol, and (iv) dried under vacuum at room temperature for $1 \mathrm{~h}$ before use.

\subsection{Spin finish oil}

Two spin finish oils were investigated in this study: (i) spin-finish epoxidized soybean oil (SFSB-oil, Sigma Aldrich) (Figure A.1) and (ii) spin finish oil extracted from stored commercial PET fabrics by Soxhlet extraction processing (SF-Ext).

SFSB-oil has been used for the spin finish treatment of Lars commercial PET $_{2009}$ and 2018 fibers. In contrast, the spin finish oil used for $\mathrm{PET}_{1993}$ was not identified and no longer used. SFSB-oil degradation from PET fabric storage was compared to that of SF-Ext from PET 1993 fibers.

\subsection{Purification of Sodium (4-styrene sulfonate) (NaSS)}


Monomer NaSS was purified by a re-crystallization process [11,23] as follows: $90 \mathrm{~g}$ of NaSS was dissolved in a mixture of ethanol and distilled water $(9: 1, \mathrm{v} / \mathrm{v})$ and heated at $70^{\circ} \mathrm{C}$ for $10 \mathrm{~h}$. The solution was then filtered and left to re-crystallize at $4{ }^{\circ} \mathrm{C}$ for 24 hours. Re-crystallized NaSS monomer was collected and dried under vacuum at $30^{\circ} \mathrm{C}$ for $6 \mathrm{~h}$. The product was kept at $4{ }^{\circ} \mathrm{C}$ away from light.

\section{Methods}

\subsection{Spin finish removal (SFR) process}

Soxhlet extraction was performed at each respective solvent boiling point to remove the spin finish oil layer from PET fabrics for 6 hours, using $60 \mathrm{~mL}$ DE per $0.1 \mathrm{~g}$ fabric samples. Solvent recovery was around $60-75 \% \mathrm{v} / \mathrm{v}$. The spin finish extraction yield (E) was calculated as follows:

$$
E=\frac{m_{0}-m_{e}}{m_{0}} \times 100
$$

where $m_{0}$ is the initial mass of the PET/ oil sample; $m_{e}$ is the mass of the PET sample after solvent extraction in the spin finish removal process.

\subsection{Collection and degradation analysis of spin finish oils}

Collecting extracted spin finish oil from fibers/fabrics. Extracted DE solutions of SF oil were (i) collected by Soxhlet extractions of the different PET fabrics (PET 1993, $\mathrm{PET}_{2009}$ and $\mathrm{PET}_{2018}$ ), (ii) evaporated using a rotary evaporator (LabTech EV311 H) for $40 \mathrm{~min}, 40 \mathrm{rpm}$, water bath $30^{\circ} \mathrm{C}$ (iii) dried under vacuum and weighed until constant mass weight of the resulting oil extract residue.

Spin finish oil degradation analysis. SFSB oil $(10 \mathrm{~mL})$ was deposited on a glass disk and exposed to (i) UV radiation at $254 \mathrm{~nm}$ or (ii) $100^{\circ} \mathrm{C}$ for 10 days in air (ambient atmosphere). After UV or thermal ambient treatment, the resulting oil samples were analyzed using FTIR spectroscopy and their solubility in diethyl ether (DE) was assessed.

\subsection{Poly (4-styrene sulfonate) grafting on PET after ozonation}

Poly(4-styrene sulfonate) (PNaSS) grafting of PET fabrics consists of a two-step process [11, 23-26]: (i) fiber ozone oxidation (ozonation) and (ii) monomer radical-initiated thermal grafting (polymerization/grafting from). This process was performed on each solvent-extracted PET fabric sample $(3 \mathrm{~cm} \times 3 \mathrm{~cm})$.

i. Ozonation: three PET fabric samples were placed in a glass reactor in which ozone gas (generator BMT $802 \mathrm{~N}, 0.6$ bar, $0.6 \mathrm{~L} / \mathrm{min}$ ) was left bubbling in water for $10 \mathrm{~min}$ at $30^{\circ} \mathrm{C}[11,23]$. The generated 
$\mathrm{O}_{3} / \mathrm{OH}^{\circ}$ mixture activates PET surfaces creating peroxide and hydro peroxide groups [24-26].

ii. Polymerization/grafting from: Three freshly ozonized PET fabrics were quickly placed in $60 \mathrm{~mL}$ degassed aqueous NaSS solution $\left(0.7 \mathrm{~mol} . \mathrm{L}^{-1}\right)$ under argon atmosphere at $70^{\circ} \mathrm{C}$ under stirring for 1 hour for the polymerization grafting-from reaction $[10,11,23]$. Peroxide groups created by the ozonation step were decomposed by $70^{\circ} \mathrm{C}$ heating to generate radicals on the fiber surface from which $\mathrm{PNaSS}$ polymerization can initiate and propagate. These polymer functionalized samples were then extensively washed in distilled water for at least $48 \mathrm{~h}$ then freeze-dried under vacuum. PNaSS grafting of PET samples without SFR - i.e. PET fabric pieces without solvent extraction but with ozonation - was performed under the same conditions first control. Non-functionalized PET fabrics undergoing only SFR (no ozonation) were also used as a second control.

\subsection{Quantification of PNaSS polymer grafting on PET surfaces by toluidine blue (TB) colorimetric assay}

PNaSS grafting rate (GR), that is, the amount of grafted sulfonate groups per mass of PET surface, on solvent-extracted PET samples was determined. Toluidine blue (TB) dye-depletion assay was used for quantitative analysis of sulfonate groups present on PET surface since one molecule of TB quantitatively complexes one sulfonate group. This method has been previously described in detail [11, 23].

Briefly, PNaSS-grafted PET fabrics were cut into pieces $(1 \mathrm{~cm} \times 1 \mathrm{~cm})$. Each PET fabric sample was incubated in $5 \mathrm{~mL}$ of $0.5 \mu \mathrm{mol} . \mathrm{L}^{-1} \mathrm{~TB}$ solution $(\mathrm{pH} 10)$ for $6 \mathrm{~h}$ at $30^{\circ} \mathrm{C}$ to achieve equilibrium complexation of TB/sulfonate groups $(n=3)$. TB-dyed fabric was 3-times washed with $5 \mathrm{~mL}$ of sodium hydroxide ( $1 \mu \mathrm{mol} . \mathrm{L}^{-1}$ aqueous solution) for $5 \mathrm{~min}$, then incubated in $10 \mathrm{~mL}$ aqueous acid acetic solution $(50 \%, v / v)$ for quantitative decomplexation. The resulting TB concentration of the TB solution removed from PNaSS-grafted PET fabric was determined by UV-vis absorption measurement at $636 \mathrm{~nm}$ considering the TB concentration calibration curve. PNaSS GR $\left(\mu \mathrm{mol} . \mathrm{g}^{-1}\right)$ was calculated as the following:

$$
G R=\frac{A \times V}{\varepsilon \times l \times m}
$$

Given $A$ as the measured optical absorption value of the TB decomplexation solution at $636 \mathrm{~nm}, \mathrm{~V}$ for the acid acetic volume (here $10 \mathrm{~mL}$ ), $\varepsilon$ for the molar extinction coefficient of TB determined from fresh TB solution and the optical density calibration curve (47000 to $\left.50000 \mathrm{~L} \cdot \mathrm{mol}^{-1} \cdot \mathrm{cm}^{-1}[10,23]\right)$, I is path length $(1 \mathrm{~cm})$, and $\mathrm{m}$ is sample mass $(\mathrm{g})$.

Nonspecific TB complexation in the case of aged or oxidized surfaces could be a limitation of this method; therefore, the reference TB value was that for TB binding to non-grafted PET fabric. Three samples were used for each analyzed surface. 


\subsection{FTIR surface characterization}

Attenuated Total Reflection-Fourier Transformation Infrared spectroscopy (ATR-FTIR) (Perkin Elmer Spectrum Two, PerkinElmer) with single reflection diamond crystal ATR cell (128 scans, $4000-400 \mathrm{~cm}^{-1}$ range, and $2 \mathrm{~cm}^{-1}$ resolution) was performed at room temperature (ambient atmosphere). Chemical characterization of SF oils and PET fabrics before and after the different treatment steps (i.e., SF as supplied, SF solvent removal, ozonation, PNaSS grafting) was performed and analyzed using Spectrum10 software. The ATR crystal was extensively cleaned by ethanol and re-calibrated before each experiment.

- A bundle of PET fibers was placed and pressed onto the crystal for analysis $(n=5)$

- SFSB and SF-Ext oil were dropped directly onto the clean crystal for analysis $(n=5)$. In this case, DE or n-hexane or THF were used to clean the crystal and a new ATR reference calibration was collected.

\subsection{Analysis of fiber surface morphology and surface nano- mechanical properties}

Surface morphology of PET fibers and fabrics samples was observed by Scanning Electron Microscopy (SEM) (TM3000, Hitachi-HighTech) and by Atomic Force Microscopy (AFM) (Multimode-8, Brücker) at room temperature. In addition, the AFM apparatus is equipped with Peakforce-Quantitative Nano Mechanical (Peakforce-QNM) capability, a tapping mode integrated into the AFM system that allows (i) high resolution imaging, (ii) resolving differences in surface mechanical properties, (iii) quantifying mechanical properties by mapping on the nanometric scale the height, stiffness, elasticity and adhesion from surface force curves. Scanning was carried out in air with a silicon tip (triangular cantilever and rotated symmetric tip), on silicon nitride cantilever with reflective aluminum. Probe parameters include single probe cantilever with frequency $f_{0}=70 \mathrm{kHz}$ and spring constant $\mathrm{k}=0.4 \mathrm{~N} / \mathrm{m}$. Calibrating deflection sensitivity was performed for each experiment. The tip radius after absolute calibration is $1.78 \mathrm{~nm}$. NanoScope Analysis 1.5 software was used. Measurement of Young's modulus from the different fiber surfaces used the Force Volume program. Calibrating deflection was performed for each experiment: 3 areas $(1.5 \mu \mathrm{m} \times 1.5 \mu \mathrm{m})$ on 3 different samples (under the same conditions) were analyzed.

\subsection{Differential scanning calorimetric analysis}

Differential scanning calorimetric (DSC) analysis was applied to measure the thermal transitions of PET fabric samples, and PET virgin film as control, before and after treatments using a DSC 8000 calorimeter (Perkin Elmer, Waltham, USA). Scanning was carried out under nitrogen atmosphere $\left(\mathrm{N}_{2} 20 \mathrm{~mL} / \mathrm{min}\right.$, 2 bar) from $0{ }^{\circ} \mathrm{C}$ to $300^{\circ} \mathrm{C}$ with a heating rate of $10^{\circ} \mathrm{C} \cdot \mathrm{min}^{-1}$, and results collected from the first scan $(\mathrm{n}=$ 3). Changes in observable thermal transitions of PET fabric samples as a function of sample age, degradation, oxidation and grafting reactions were analyzed, in particular, by variations in the PET melting enthalpy. 


\section{Results}

\subsection{Spin-finish oil degradation}

The ATR-FTIR spectra of virgin spin finish epoxidized soybean oil (SFSB) $[27,28]$ before and after accelerated degradation/aging by UV radiation $(254 \mathrm{~nm})$ or heating at $100^{\circ} \mathrm{C}$, are presented in Fig. 1 . Spectral analysis provided evidence for the degradation mechanism of the extracted SF oil from PET fabrics. As shown in Fig. 1, UV-irradiation induced chemical modification to the SFSB oil illustrated by the appearance of a new vibrational band at $1644 \mathrm{~cm}^{-1}$ attributed to $C=C$ vibration (see Fig. $1 \mathrm{C}$ ), whilst thermal treatment led to the appearance of a sharp band at $3696 \mathrm{~cm}^{-1}$ attributed to free $\mathrm{O}-\mathrm{H}$ stretching (see Fig. 1B). UV irradiation create radicals that yield epoxy ring opening, leading to new $\mathrm{C}(\mathrm{OH})=\mathrm{C}$ bonds (scheme Fig. 2) ; this correlates to the appearance of the $\mathrm{C}=\mathrm{C}$ band at $1644 \mathrm{~cm}^{-1}$ and the shoulder for the $\mathrm{C}(\mathrm{OH})$ at $3006 \mathrm{~cm}^{-1}$. Thermal effects are evidenced by generated $\mathrm{OH}$ groups' sharp band at $3696 \mathrm{~cm}^{-1}$, attributed either to fatty acid oxidation or epoxide ring opening [29] (scheme Fig. 2). SFSB oil under thermal treatment reduced the acyl chain $R_{1}-C\left(R_{2}\right)=0$ vibrational band intensity at $1324 \mathrm{~cm}^{-1}$ (see Fig. 1D) [30, 31]. Additionally, the $C-O$ stretching vibration shifts from 1296 to $1284 \mathrm{~cm}^{-1}$ under thermal treatment (Fig. 1D), indicating that heating increases $\mathrm{C}-\mathrm{OH}$ group formation $[32,33]$ and hydrogen bond formation between the molecules. On the other hand, both thermal and UV treatments intensified the SFoil degradation by chain scission at the ester position and epoxy ring opening (decrease of $874 \mathrm{~cm}^{-1}$ peak) to form $-\mathrm{OH}$ and $\mathrm{C}=\mathrm{C}$ chemistry $[29,34]$.

To summarize, two kinds of epoxy ring opening reactions are observed (see scheme Fig. 2): reaction (1) heating leading to hydroxyl group generation, and reaction (2) UV treatment leading to de-hydroxylation reactions and resulting in alkene $\mathrm{C}=\mathrm{C}$ double bond formation.

\subsection{Spin finish removal and polymer functionalization of long-term stored PET fabrics \\ 4.2.1. Spin finish removal process}

Spin finish removal (SFR) of PET fabrics exploited Soxhlet extraction using three solvents selected for their ability to strongly solubilize SFSB oil and efficiently extract oil from the fabric while not affecting PET. Extraction from the selected solvents, $n$-hexane, DE and THF, and PNaSS grafting were investigated (see Fig. 3). Solvents have generally weak polarities varying in the same direction as their dielectric constants, i.e. decreasing from THF to DE to n-hexane: $\varepsilon_{\mathrm{THF}}=7.5, \varepsilon_{\mathrm{DE}}=4.3$ and $\varepsilon_{\mathrm{n} \text {-hexane }}=1.8$.

The oil extraction yield was ranged from 1.2 to $1.4 \%$. The extracted DE solution was evaporated to obtain the extracted oil from PET fabrics for analysis. N-hexane (boiling point $68^{\circ} \mathrm{C}$ ) and THF (boiling point $66^{\circ} \mathrm{C}$ ) were used as alternative extraction solvents to investigate chemical changes in spin finish oil (e.g., 
changing solubility from degradation, oxidation) from oil-coated ligaments. However, n-hexane is reported to have limited extraction efficiency for soybean oil derivatives,[35] and THF could damage PET [36].

Spin finish PET fabrics studied here are divided into two types: (a) long-term stored PET fabrics produced in 1993 (PET 1993 ) that remained in contact with SF oil for over 26 years before SFR; and (b) mid-to-short term stored PET fabrics produced in 2009 (PET 2009) and 2018 (PET 2018), remaining ten and two years, respectively, in contact with SF oil before SFR. All fabrics were stored in the same non-controlled ambient storage environment, except for temperature that was maintained near $20^{\circ} \mathrm{C}$.

However, SF oil Soxhlet extraction efficiency was strongly modified by storage time duration between SF PET treatment and SFR: the longer the PET storage, the less effective the SFR extraction. Results expressed in \% of extracted SF oil after 6 hours of solvent reflux (see Fig. 3A) showed that extraction yields of more recent PET sheet fabrics produced in 2018 reached $1.4 \%$ and $0.87 \%(w / w)$ using DE and $n-$ hexane, respectively. By comparing the $1.4 \%$ extraction yield of the most recent PET (PET 2018) fabric with the initial SF content, the extraction conditions and yields are seemingly optimized. However, PET fabrics produced in 2009 exhibited a $15 \%$ and $80 \%$ decrease in extraction yield for DE and for $n$-hexane, respectively (i.e., to $1.2 \%$ and $0.3 \%$, respectively). In addition, an unexpected, excessive amount of extracted oil was obtained from PET fabrics produced in 1993 (56\%, w/w) from the unidentified SF oil chemistry applied at that time.

To investigate the deleterious effect of these different storage times on subsequent PET PNaSS GR, DE, n-hexane or THF were used for SF oil removal before performing PNaSS grafting on the two aged fabrics, PET 2009 and PET 2018 (see Fig. 3B). Results presented in Fig. 3B showed that:

- For PET 2018 , the obtained PNaSS GR was on the order of those already described by Ciobanu et al. (i.e., from 1 to $3 \mu \mathrm{mol} / \mathrm{g}$ ) [10].

- For PET 2009, the decreased obtained PNaSS GR can be related to the reduced SFR efficiency and oil extraction yield due to extended storage.

THF extraction produced the highest effective SF oil removal compared to DE and $n$-hexane. This directly improves PNaSS GR for $\mathrm{PET}_{2009}$ which reached the GR value of $\mathrm{PET}_{2018}$ fabrics, whereas DE and nhexane extractions reduced the $\mathrm{PET}_{2009} \mathrm{GR}$.

\subsubsection{Spin finish oil extracted from PET products}

Finishing oil degradation was analyzed by FTIR spectroscopy. The IR spectra of the different oil extraction processes from $\mathrm{PET}_{1993}, \mathrm{PET}_{2009}$ and $\mathrm{PET}_{2018}$ are displayed in Fig. 4. Results show significant differences between spectra of virgin SF oil (non-degraded) and oil solvent-extract spectra from $\mathrm{PET}_{1993}$, $\mathrm{PET}_{2009}$ and $\mathrm{PET}_{2018}$ fabric samples. $\mathrm{PET}_{1993}$ oil extracted from 26-year storage showed (i) a strong and broad $\mathrm{OH}$ peak at $3358 \mathrm{~cm}^{-1}$ (Fig. 4B); (ii) a $1626 \mathrm{~cm}^{-1} \mathrm{C}=\mathrm{C}$ stretching bond vibrational intensity overwhelming that for $\mathrm{C}=0$ at $1734 \mathrm{~cm}^{-1}$ (Fig. 4C) that declines [37]. The emerging $\mathrm{C}=\mathrm{C}$ bond vibration 
could be generated by UV exposure of the oil through epoxy ring opening [38] (see scheme in Fig. 2). The epoxy vibration identified at $950 \mathrm{~cm}^{-1}$ dissappeared for extracted oil from $\mathrm{PET}_{1993}$ and decreased for PET $_{2018}$ and 2009 oil samples compared to virgin SF-oil (see Fig. 4D).

\subsubsection{Degraded oil interaction with PET fiber surfaces}

To explain the observed reduced PNaSS GR on mid-to-long storage time PET samples, we analyzed the reduced efficiency of SFR and the SF oil remaining on PET 2009 , and 1993 samples. FTIR spectra of these sample PET fabrics, presented in Fig. 5 A, show peaks at $2850 \mathrm{~cm}^{-1}$ and $2918 \mathrm{~cm}^{-1}$, characteristic of asymmetric $\mathrm{C}$-H stretching $\left(2918 \mathrm{~cm}^{-1}\right)$ and symmetric $\mathrm{C}-\mathrm{H}$ stretching $\left(2850 \mathrm{~cm}^{-1}\right)$ vibrations from methylene groups of both non-degraded SF-oil and degraded SF-Ext oil (Fig. 5B and Fig. 5C).

\subsection{SEM and DSC analysis of PET fiber surface alterations at the degraded oil/fiber interface}

\subsubsection{SEM analysis}

The observed chemical alterations of PET spin finish oil with storage prompted further analysis of PET fiber structure using scanning electron microscopy (SEM). SEM images of the different aged PET fabrics

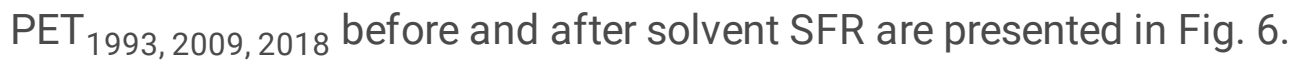

Results showed: (i) that PET fiber surfaces of all ages were smooth before SFR, (ii) remaining oil or surface contaminants after SFR when using DE are evident as round or spread droplets on PET 1993 and $\mathrm{PET}_{2009}$ (yellow arrows, Fig. 6), whereas no such evidence is detected on $\mathrm{PET}_{2018}$.

Remaining oil or surface contaminants after SFR of these PET fabrics from the two longer storage times evidences the reduction in oil solubility and extraction in DE solvent with aging. This confirms strong PET surface interactions with adsorbed, degraded finish oil. Longer storage indicates degradation of the PET interface and/or changes in the finishing oil over time.

\subsubsection{DSC analysis}

PET fabrics from different storage times ( $\mathrm{PET}_{1993}, \mathrm{PET}_{2009}, \mathrm{PET}_{2018}$ ) and a PET reference film used as control were analyzed by Differential Scanning Calorimetry (DSC). DSC scans carried out before and after SFR for fabrics are presented in Fig. 7 and compared to that of PET control (virgin semi-crystalline PET film). The analysis and comparison of the different scans showed:

i. differences in the PET melting temperatures $\left(T_{m}\right)$ between PET control (one peak at $255^{\circ} \mathrm{C}$ ) and PET fabrics/fibers (two melt peaks - first around $250^{\circ} \mathrm{C}$ and second at $255-258^{\circ} \mathrm{C}$ ). These differences can be explained by the different samples processing - flat extrusion for the PET control and extrusion plus stretching followed by specific heat treatment for the PET fibers used to weave the 
fabrics. Extrusion and heating treatment may strongly modify the crystalline structure of a thermosensitive polymer such as PET; in the case of fiber extrusion, the application of tensile stress increases again the orientation of macromolecular chains leading to partial crystallization and increases to the $T_{m}$. The appearance of double $T_{m}$ peaks has been attributed to different polymer crystal lamellae thickness [39]. Kong and Hay demonstrated that the secondary melt peak was produced by polymer re-crystallization of the thickest lamella.

ii. DSC scans of spin finish PET fabrics - i. without SFR - are very similar whatever the storage time, indicating that the presence of spin finish oil maintains the integrity of the fibers and fabrics,

iii. The effect of SFR on the DSC profile is strongly dependent on solvent extraction efficiency:

- N-hexane being the less efficient solvent for the SFR process led to similar DSC profiles for the three samples because the solvent can only extract the superficial layer of oil on fabrics;

- DE was demonstrated to be more efficient solvent for SFR. DE extracted the oil from PET 2018 and 2009 in a similar way, giving identical DSC scans, whereas for PET 1993, DE dissolved the oil plus the oil/degraded PET layer, revealing the degraded characteristics of PET on the DSC with peaks attributed to PET oligomers (two first peaks) and the melting peak $\left(255^{\circ} \mathrm{C}\right)$ of the remaining solid PET [40].

DSC was not sufficiently sensitive to directly demonstrate PET degradation, but was useful to discern the differences in solvent extraction efficiencies. DSC scan differences between DE and hexane extracted samples emphasized the differences in the aging of the PET samples.

\subsection{Topography and surface mechanical parameters of long-term stored PET 1993 and 2009 fabrics before and after PNaSS surface functionalization.}

\subsubsection{Fiber topography analysis}

AFM analyses of PET fabrics samples before and after PNaSS functionalization are presented in Fig. 8. The method seeks to compare effects of surface treatments including spin-finish removal (SFR) and presence or absence of PNaSS grafting on the PET surface topography ans surface mechanics from samples of different storage durations. Similar to SEM imaging (Fig. 6), finishing oil residues still present on PET surfaces after SFR by DE are detected by 3D topographical imaging of both non-grafted and PNaSS-grafted PET 1993 . AFM imaging allowed further demonstration that before PNaSS grafting, $\mathrm{PET}_{1993}$ fiber surfaces are still covered by oil or oil-swollen PET layers as reflected by surface roughness values ( $\mathrm{Sa}$ ) equaling $2.164 \pm 0.4 \mathrm{~nm}$. This Sa value was higher than that observed for both non-grafted $\mathrm{PET}_{2009}$ and $\mathrm{PET}_{2018}$ fibers, respectively (i.e., $1.04 \pm 0.2 \mathrm{~nm}$ and $0.94 \pm 0.8 \mathrm{~nm}$, respectively). Additionally, after PNaSS grafting, surface roughness of PET 1993 fibers increased to a Sa value of $5.18 \pm 0.8 \mathrm{~nm}$, much higher than that for non-grafted and other samples. In fact, the surface textures of PNaSS-grafted $\mathrm{PET}_{1993}$ are divided into basic two types: (a) smooth and (b) rough surfaces (Fig. 8). This is explained by influences or differential effects of the PNaSS functionalization process in the presence or absence of finishing oil residue. Region (a) results from removing the finishing oil layer during the ozonation and 
PNaSS grafting, hindering peroxide generation and PET fiber surface etching, while residual oil layer in region (b) remained on the PET surface despite SFR, limiting polymer grafting and ozone etching.

In contrast, the entire surfaces of $\mathrm{PET}_{2018}$ and $\mathrm{PET}_{2009}$ were "cleaner" after SFR with quite low surface roughness, $\mathrm{Sa}=1.04 \pm 0.2 \mathrm{~nm}$ for $\mathrm{PET}_{2018}$ and $0.94 \pm 0.8 \mathrm{~nm}$ for $\mathrm{PET}_{2009}$. A slight increase in surface roughness was recorded for $\mathrm{PNaSS}_{\text {grafted }} \mathrm{PET}_{2018}$ and $\mathrm{PET}_{2009}$ fibers, with Sa values of $1.28 \pm 0.5 \mathrm{~nm}$ and $1.07 \pm 0.4 \mathrm{~nm}$, respectively. This corresponds to the increased PNaSS GR (see Fig. 10) and demonstrates the efficiency of DE SFR treatment and resulting PNaSS grafting of these PET fabric samples after oil removal.

\subsubsection{Peakforce Quantitative Nano-Mechanical Properties AFM analysis}

AFM force curves and Young's modulus changes confirm surface property modification of PET samples after the different storage, treatments and processes. AFM force curves were collected by the Force Volume program. Retracted force curves on $\mathrm{PET}_{2018}$ surfaces for both virgin and non-functionalization are clearly higher than others. This is evidence for a harder surface of the newer PET fiber [41]. Likewise, low deflection error collected from $\mathrm{PET}_{2009}$ and $\mathrm{PET}_{1993}$ fibers is associated with interactions between cantilever tip and soft and wettable surfaces [41, 42]. This demonstrates and supports further PET surface modification from the oil - either the oil itself and resulting surface interactions are physically and/or chemically changed, or the PET surface is changed. Possibly, polymer and finishing oil degradation resulting in chain scission occurs on these two samples.

PET surface Young's modulus was measured by the Peakforce Quantitative Nano-Mechanical properties AFM (Peakforce QNM) (Fig. 9). Young's modulus (Fig. 9B) of SFR non-

grafted $\mathrm{PET}_{2018}$ was measured to be $2.3 \mathrm{GPa}$ (comparable to 2-4 GPa from literature [2, 42]) and much lower values obtained for non-grafted $\mathrm{PET}_{2009}\left(\mathrm{E}_{\mathrm{Y}}=85 \mathrm{MPa}\right)$. Young's modulus for non-grafted $\mathrm{PET}_{1993}$ decreased significantly $\left(E_{Y}=63 \mathrm{MPa}\right)$. After PNaSS grafting, $E_{\gamma}$ of grafted $\mathrm{PET}_{2018}$ was substantially reduced to $85 \mathrm{MPa}$ resulting from the new, lower modulus PNaSS layer combined with likely minor surface changes from PET functionalization processes [23]. Non-grafted PET 2009 shows a lower Young's modulus (85 MPa) with further modulus reduction after polymer grafting, similar to that of PET 2018. Nongrafted and grafted $\mathrm{PET}_{1993}$ fiber surface moduli were both changed slightly $\left(\mathrm{E}_{\gamma}\right.$ is about $\left.50-63 \mathrm{MPa}\right)$.

Such changes observed in Young's surface modulus possibly correlate with PNaSS grafting efficiency (GR) on each PET sample. Indeed, the high $\mathrm{PET}_{2018}$ Young's modulus value of $\mathrm{E}_{\mathrm{Y}}=2.3 \mathrm{GPa}$ reflects an intact non-degraded PET surface. Grafting processes decrease the $\mathrm{PET}_{2018}$ surface modulus to $87 \mathrm{MPa}$ (96\% decrease). Substantial surface PET oxidation under ozonation promotes efficient PNaSS grafting from this PET surface. For PET 2009 , Young's modulus of non-grafted fiber samples is similar to the grafted $\mathrm{PET}_{2018}$ fiber surface, attributed to PET fiber surface degradation by PET and SF oil oxidation during long-term storage, even though this PET fabric sample was covered by SF oil, and then further 
surface degradation from the polymer grafting protocol. The observed $\mathrm{E}_{\mathrm{\gamma}}$ reduction of $\mathrm{PET}_{2009}$ from ungrafted $85 \mathrm{MPa}$ to grafted $60 \mathrm{MPa}$ (decrease of $29 \%$ ) reflects these similar surface alteration phenomena as with $\mathrm{PET}_{2018}$. Overall, the $\mathrm{E}_{\mathrm{Y}}$ for grafted $\mathrm{PET}_{2009}$, non-grafted $\mathrm{PET}_{1993}$, and grafted $\mathrm{PET}_{1993}$ were similar (50-63 MPa), reflecting roughly equivalent PET surface physical states for these fabrics after these aging and surface treatments.

While these results support limited degradation of $\mathrm{PET}_{2009}$ fibers from polymer grafting, the topography (Fig. 8) and Young's modulus measurement (Fig. 9) on PET 2009 support their usability. To improve the GR

for $\mathrm{PET}_{2009}$, a further study using increased fiber grafting temperature (Fig. 10) shows that PNaSS GR could attain $1 \mu \mathrm{mol} . \mathrm{g}^{-1}$, similar to the GR for $\mathrm{PET}_{2018}$.

\subsection{PNaSS grafting rate (GR) measurements}

Colorimetric Toluidine Blue (TB) dye binding was used to determine the PNaSS GR for PET 2009 and $\mathrm{PET}_{2018}$ surfaces after solvent extraction with DE and then different ozonation times. GR results versus ozonation time, presented in Fig. 10, show that for $\mathrm{PET}_{2009}$ fabrics (i.e., ten year storage), GR saturates after 20 min of ozonation whereas GR of PET 2018 increases gradually from 0.6 to $1.6 \mu \mathrm{mol} . \mathrm{g}^{-1} . \mathrm{h}^{-1}$ with increasing ozonation time $[10,23]$. Nonetheless, the effects of different SF oil chemistry and resultant degradation and oxidation in storage, subsequent interactions with PET fiber surfaces and ambient water, and extraction efficiency in SFR based on these chemical transformations are all clearly involved in the final fiber ozonation functionalization efficiency and therefore the fiber GR.

\section{Discussion}

\subsection{Influence of ozonation exposure and spin-finish oil/PET interaction on the reactivity of PET surfaces during polymer graft functionalization}

\subsubsection{Ozonation exposure}

Functionalization of PET fibers/fabrics by ozonation and PNaSS grafting was performed on the different aged and extracted PET fabric surfaces. PNaSS GR for PET fabrics 1993, 2009 and 2018 was measured using the TB colorimetric assay (Fig. 3B and Fig. 10). Only a fraction of the radicals generated during this ozonation and thermal polymerization "grafting from" process are presumed to actually participate in initiating NaSS polymerization and grafting from each PET surface. Indeed, each radical will not initiate a single PNaSS grafted chain due to known competition between polymerization from surface radicals and those initiated in solution, disproportionation effects, and radical quenching by other species in the system. Surface radicals may be "de-activated" to non-reactive hydroxyl groups $(-\mathrm{OH})$ before encountering NaSS monomer molecules [1, 24, 25]. Therefore, PNaSS-grafted surfaces are functionalized by propagating $\mathrm{PNaSS}$ chains while also generating $-\mathrm{OH}$ surface groups from hydrolyzed peroxide. Increasing GR with increased ozonation time demonstrates that more peroxide groups are continually generated on $\mathrm{PET}_{2018}$ surfaces to provide radicals for initiating NaSS polymerization [10, 23] (Fig. 10). In 
contrast, $\mathrm{PET}_{2009}$ fiber surfaces do not generate radicals/-OH groups with increased ozonation time (Fig. 10), implying that $\mathrm{PET}_{2009}$ surfaces are degraded and chemically compromised before functionalization.

5.1.2 Effect of oil/PET interaction after long-term storage on spin finish removal and functionalization Sizing or spin finish (SF) treatment is widely used in the textile industry to improve fiber extrusion and handling for enabling further knitting or weaving of fabrics. Nevertheless, before starting any additional fiber or fabric surface treatments - here, the required PNaSS grafting of PET fabrics to make it biocompatible - ideally, total removal of the spin finish oil is required using SFR methods. Indeed, SFSB oil residue prevents polymer radical initiation and PET surface grafting; therefore, instead of initiating polymerization, radicals will induce oil degradation and prevent PNaSS-PET surface grafting to proceed as desired.

Degradation of SF oil on long-term stored PET fabrics was investigated. Combining the extraction yield (55.6\% extracted oil collected from PET ${ }_{1993}$ ) (Fig. 3A) and FTIR results (Fig. 4 and Fig. 5) provides clear evidence for formation of hydroxylated fatty acids that promote strong water adsorption from a possibly moist ambient environment (Fig. 1 and Fig. 4). These results support that, for long-term storage, oil degradation was sufficient to produce oil by-products [22].

The solubility of finishing oil extracted into SFR non-polar solvents decreased in the following order: THF $>$ diethyl ether $>n$-hexane (see supporting information Figure A.2). This partly explains the significantly increased oil extraction yield for $\mathrm{PET}_{1993}$ where degraded finishing oil increased extracted oil product mass considerably (Fig. 3).

Additionally, spin finishing oil present after longer fiber storage times can degrade/modify PET surfaces as well as the SF oil as shown in Fig. 4. This changes the SFR result and might also lead to inhibited or limited ozonation activation steps on these surfaces. Aging and degradation are reported to induce a very low-to-none peroxide generation on $\mathrm{PET}_{2009}$ fabrics: PET surfaces were hydrolytically degraded, leading to chain scission and producing hydroxyl groups that prevent peroxide generation $[1,26,39,43]$. Particularly, due to aging, PET $_{1993}$ fabrics no longer comprise virgin PET fibers but have become PET fibers highly impregnated with degraded oil (Fig. 6 and Fig. 8); the outer polymer surface layer of the PET fibers comprises a polymer/oil mixture (Fig. 5) [21, 29, 44]. Therefore, long-term storage of spin finishtreated PET fabrics or fibers compromises SFR, increases PET surface degradation and lowers PNaSS GR.

These collective results suggest that without proper storage precautions, or under UV and/or oxygen/water exposure from ambient atmosphere, oil and PET surfaces could be chemically degraded as follows:

i. radicals can be generated on PET macromolecular chains as described [26], producing chain cleavage and oxidation chemistry as evidenced in altered surface FTIR/ATR spectra (Figs. 1 and 2) and in Young's modulus by AFM (Fig. 8); 
ii. unsaturated hydrocarbon chain olefin bonds and epoxides in spin finish-derivatized soybean oil [37, $38,45,46]$ promote free radical generation and oil oxidation (Figs. 1 and 2);

iii. radical and/or oxidative chemistry propagation to and cross-linking of oil-PET at the fiber interface can occur [29] (Fig. 5, Fig. 6, and Fig. 8);

iv. degraded oil is chemically distinct from virgin oil and can also interact with degraded PET surfaces

(Fig. 2) $[1,26,39]$ through new hydrogen bonds via oxidation by-products (see Fig. 6);

v. Water can be absorbed onto/into the more polar oxidized PET/oil fiber surface, leading to swelling of oil layers and increased mass of extracted oil with more polar solvents (Fig. 3 and Fig. 4).

The scheme in Fig. 11 provides different possible chemical effects of $\mathrm{UV}$ and $\mathrm{O}_{2}$ oxidation agents on oil/PET chemical transformations and interactions over time.

In addition, should spin finish oil be unstable to air and light exposure, then SFR should best be achieved rapidly post-production of PET fibers and fabrics, or storage should be performed more vigilantly in the absence of air or light. Otherwise, finishing oil will chemically transform from desirable hydrophobic protective, lubricating coating states to hydrophilic chemistry via oxidation and/or hydrolysis, and may generate propagating radicals. Long-term finished PET fiber storage in the presence of degraded oil enhances: (a) generation of fiber surface hydroxyl groups, water absorption and oil/water emulsion formation at fiber surfaces; and (b) hydrolytic PET surface degradation that can then bond or imbibe this oil-water mixture [22, 39].

\subsection{Evaluating PET fabrics based on fiber surface nano- mechanical properties}

PET surface modifications from aging, storage, SFR or not, grafting or not, and degradation of PET fibers/fabrics were analyzed by AFM (Fig. 8). The surface Young's modulus distribution reflects relative PET fiber hydrolytic degradation. The highest surface Young's modulus was found for PET 2018 after DESFR, whereas softer surfaces from $\mathrm{PET}_{2009}$ and $\mathrm{PET}_{1993}$ reflected PET-oil interactions and possible polymer chain scission prior to grafting $[41,42]$. More extensive time-dependent degradation/oxidation for SF oil on $\mathrm{PET}_{1993}$, with or without polymer grafting, show similar results to deliberate ozonation plus time-dependent aging effects plus polymer grafting shown for $\mathrm{PET}_{2009}$. The surface modulus for $\mathrm{PET}_{1993}$ does not change further after ozonation or functionalization, consistent with terminal degradation effects on non-grafted $\mathrm{PET}_{1993}$ surfaces from oxidative PET surface polymer chain scission.

Deleterious effects on PET fibers from finishing oil aging were assumed to derive from:

i. Finishing oil degradation: the spin finish oil used for $\mathrm{PET}_{2009}$ and $\mathrm{PET}_{2018}$ is derived from modified soybean oil and is FDA-approved for fibers/fabrics dedicated to medical devices, but not inert.

ii. Finishing oil degrades, interacts and swells $\mathrm{PET}_{1993}$ surfaces in long-term storage (AFM topography,

Fig. 8). SFR oil removal extracts an excessive amount of mass from these aged fiber samples 
(Fig. 1A), indicating that the imbibed finishing oil plus any PET-degradation soluble products are extracted from these oil-swollen PET fabrics.

\section{Conclusions}

Evaluation of the influence of spin-finish oil and storage on PET fabric degradation and fiber surface functionalization with anionic polystyrene sulfonate applied to PET fabric in clinical grade ligament prostheses is reported. To understand relationships between SFR extraction and PNaSS grafting on PET fiber properties, storage times for finishing oils on PET fabrics before their removal by SFR extraction, and the chemical nature of spin finish oil aging was analyzed.

Results highlight the importance of the following parameters on PET fiber surface quality in storage: (i) the nature of the spin finish oil; (ii) the storage time and conditions for spin finished PET fabrics; (iii) the choice of SFR solvent for spin finish removal in order to optimize solvent extraction efficiency and further functionalization of PET fibers and fabric surfaces.

Our data suggest a SF oil and PET degradation mechanism involving finishing oil chemistry and aging (i.e., oxidation in situ) that promotes PET surface degradation. Storage conditions facilitate chemical transformations and resulting interactions for degrading spin finish oil with PET, producing new PET/oil surfaces exhibiting (i) resistance to SF oil removal by solvent extraction, (ii) reduced surface activation and functionalization using PNaSS polymer grafting-from processes; (iii) likely chemical and physical surface compromises to PET fibers and fabrics from prolonged interactions with degraded SF oil, and (iv) changes in PET fiber surface chemistry and surface mechanical properties. The longer the fiber storage time, the more evident the SF oil changes, the more evident the PET fiber degradation, the lower the PET surface PNaSS GR, and the lower the PET surface mechanical integrity. Different PET surface changes based on spin finish oil, storage time, and grafting-from processing were investigated through AFM analyses. Surface roughness and Young's moduli for the different PET fiber surfaces were distinct for PET fibers before and after surface functionalization and correlated with time-dependent production of long-term storage degradation products from both oil and PET. These results have profound implications for PET fiber processing and storage, with even more important consequences for the integrity and reliability of medical grade PET fabrics used in numerous implant devices.

\section{List Of Abbreviations}

AFM, atomic force microscopy;

$\mathrm{DE}$, diethyl ether;

DSC, Differential Scanning Calorimetry;

FTIR, Fourier Transform Infrared Spectroscopy; 
PET, polyethylene terephthalate;

NaSS/ pNaSS, sodium 4- styrene sulfonate/ poly(sodium 4- styrene sulfonate);

SFR, Spin Finish Removal;

SEM, Scanning Electron Microscopy;

THF, tetrahydrofuran;

TB, Toluidine Blue;

UV, ultraviolet

$\mathrm{PET}_{1993}$, polyethylene terephthalate ligament fibers produced from fiber knitting in 1993

$\mathrm{PET}_{2009}$, polyethylene terephthalate ligament fibers produced from fiber knitting in 2009

$\mathrm{PET}_{2018}$, polyethylene terephthalate ligament fibers produced from fiber knitting in 2018

\section{Declarations}

Ethics approval and consent to participate (Not applicable)

Consent for publication (Not applicable)

Availability of data and material (Not applicable)

Competing interests (The authors declare that they have no competing interests)

\section{Funding}

The authors sincerely thank the French Public Investment Bank (BPI) - Future Investment Project - PSPC application - Liga2bio project (VM) for funding this work.

\section{Authors' contributions}

Tuan Ngoc Nguyen was the lead investigator on all experiments, data and text drafting work. Andre Rangel contributed to DSC experiments and analyses. David Grainger revised, edited, drafted and technically critiqued the complete manuscript content. Véronique Migonney was technical supervisor and head of the laboratory and edited the manuscript. All authors have read and approved the manuscript.

\section{Authorship}

Tuan Ngoc Nguyen: nguyentuan111190@gmail.com; principal technical contributor , conception, design and conduct of the experiments, acquisition, analysis, interpretation of data, initial draft the work; 
Andre Rangel: andre.luizreisrangel@univ-paris13.fr; ; acquisition, analysis, interpretation of data;

David Grainger: David.Grainger@hsc.utah.edu; data analysis and technical critique, substantively revised, improved and added content to the manuscript;

Véronique Migonney: veronique.migonney@univ-paris13.fr; supervisor, project conception, analysis, draft and substantively revised the work;

All authors have approved the submitted version.

Acknowledgements (Not applicable)

\section{References}

1. Wiles D, Day M. Photochemical Degradation of Poly(ethy1ene Terephthalate). III. Determination of Decomposition Products and. J Appl Polym Sci. 1972;16:203-15.

2. Bin Y, Oishi K, Yoshida K, Matsuo M. Mechanical properties of poly(ethylene terephthalate) estimated in terms of orientation distribution of crystallites and amorphous chain segments under simultaneous biaxially stretching. Polym J. 2004;36:888-98.

3. Kong Y, Hay JN. Multiple melting behaviour of poly(ethylene terephthalate). Polymer. 2002;44:62333.

4. Aronoff MS. Market Study: Biomaterials Supply for Permanent Medical Implant. J Biomater Appl. 1995;9:205-60.

5. Dieval F, Khoffi F, Mir R, Chaouch W, Le Nouen D, Chakfe N, et al. Long-term biostability of pet vascular prostheses. Int J Polym Sci. 2012;2012.

6. Kock HJ, Stürmer KM, Letsch R, Schmit-Neuerburg KP. Interface and biocompatibility of polyethylene terephthalate knee ligament prostheses A histological and ultrastructural device retrieval analysis in failed synthetic implants used for surgical repair of anterior cruciate ligaments. Arch Orthop Trauma Surg. 1994;114:1-7.

7. Mascarenhas R, MacDonald PB. Anterior cruciate ligament reconstruction: A look at prosthetics Past, present and possible future. McGill J Med. 2008;11:29-37.

8. 10.1016/j.asmart.2014.11.001

Chen T, Jiang J, Chen S. Status and headway of the clinical application of artificial ligaments. AsiaPacific J Sport Med Arthrosc Rehabil Technol [Internet]. Elsevier Ltd; 2015;2:15-26. Available from: http://dx.doi.org/10.1016/j.asmart.2014.11.001.

9. Brulez B, Laboureau J-P, Migonney V, Mihaela Ciobanu, Graciela Pavon-Djavid AS. Ligament prothetique biomimetique et procede d'obtention. WO2004067051A1; 2005.

10. Ciobanu M, Siove A, Gueguen V, Gamble LJ, Castner DG, Migonney V. Radical graft polymerization of styrene sulfonate on poly(ethylene terepthalate) films for ACL applications: "Grafting from" and chemical characterization. Biomacromol. 2006;7:755-60. 
11. Vaquette C, Viateau V, Guérard S, Anagnostou F, Manassero M, Castner DG, et al. The effect of polystyrene sodium sulfonate grafting on polyethylene terephthalate artificial ligaments on invitro mineralisation and invivo bone tissue integration. Biomaterials. 2013;34:7048-63.

12. Lessim S, Oughlis S, Lataillade JJ, Migonney V, Changotade S, Lutomski D, et al. Protein selective adsorption properties of a polyethylene terephtalate artificial ligament grafted with poly(sodium styrene sulfonate) (polyNaSS): Correlation with physicochemical parameters of proteins. Biomed Mater. 2015;10.

13. Lessim S, Migonney V, Thoreux P, Lutomski D, Changotade S. PolyNaSS bioactivation of LARS artificial ligament promotes human ligament fibroblast colonisation in vitro. Biomed Mater Eng. 2013;23:289-97.

14. Pavon-Djavid G, Gamble LJ, Ciobanu M, Gueguen V, Castner DG, Migonney V. Bioactive poly(ethylene terephthalate) fibers and fabrics: Grafting, chemical characterization, and biological assessment. Biomacromol. 2007;8:3317-25.

15. Bajaj P. Spin finishes for manufactured fibres. Manuf Fibre Technol. London; 1997. p. 139-69.

16. Elhawary IA. Spin finishes for textiles. Adv Yarn Spinn Technol. Cambridge.: Woodhead Publishing; 2010. pp. 416-30.

17. Becker W, Mathis R, Lippmann A Lubricants For Spinning Combed Wool Slivers And Methods Of Using The Same. 2005. p. U.S. Patent Application No. 10/828,639.

18. Shay BM. Low Fuming Spin Finish For Nylon Weaving Yarns. U.S. Patent Application No. US3850819A. 1974.

19. 10.1016/B978-0-935315-63-9.50025-5 Johnson LA, Myers DJ. Industrial Uses for Soybeans [Internet]. Pract. Handb. Soybean Process. Util. AOCS Press; 1995. Available from: http://dx.doi.org/10.1016/B978-0-935315-63-9.50025-5.

20. Bernholz W, Nahta R, Redston J. Textile Finish. Washington, DC: U.S; 1974.

21. Sharma BK, Perez JM, Erhan SZ. Soybean oil-based lubricants: A search for synergistic antioxidants. Energy Fuels. 2007;21:2408-14.

22. Rahman M, East $\mathrm{G}$. The effect of spin finishes on hydrolysis rates of medical grade polyester. J Appl Biomater Biomech. 2009;7:185-93.

23. Nguyen NT, Rangel A, Migonney V. Kinetic and degradation reactions of poly (sodium 4-styrene sulfonate) grafting "from" ozonized poly (ख-caprolactone) surfaces. Polym Degrad Stab. Elsevier Ltd; 2020;109154.

24. Fujimoto K, Takebayashi Y, Inoue H, Ikada Y. Ozone-induced graft polymerization onto polymer surface. J Polym Sci Part A Polym Chem. 1993;31:1035-43.

25. Li J, Wang J, Li P, Weng Y, Ren L, Fei X, et al. Ozone-induced immobilization of chitosan and heparin on polyethylene terephthalate films to improve antithrombogenic properties. Key Eng Mater. 2007;342-343:809-12. 
26. Gryn'ova G, Hodgson JL, Coote ML. Revising the mechanism of polymer autooxidation. Org Biomol Chem. 2011;9:480-90.

27. Goburdhun D, Jhaumeer-Laulloo SB, Musruck R. Evaluation of soybean oil quality during conventional frying by FTIR and some chemical indexes. Int J Food Sci Nutr. 2001;52:31-42.

28. Taheri R, Kosasih B, Zhu H, Tieu AK. Surface film adsorption and lubricity of soybean oil in-water emulsion and triblock copolymer aqueous solution: A comparative study. Lubricants. 2017;5.

29. Buddhiranon S, Chang T, Tang K, Kyu T. Stabilization of epoxidized soybean oil-plasticized poly(vinyl chloride) blends via thermal curing with genistein. J Appl Polym Sci. 2018;135:1-7.

30. Brandenburg K. Fourier transform infrared spectroscopy characterization of the lamellar and nonlamellar structures of free lipid A and Re lipopolysaccharides from Salmonella minnesota and Escherichia coil Klaus. Biophys J. 1993;64:1215-31.

31. 10.1016/j.vibspec.2014.07.001

Bensaid MO, Ghalouci L, Hiadsi S, Lakhdari F, Benharrats N, Vergoten G. Molecular mechanics investigation of some acrylic polymers using SPASIBA force field. Vib Spectrosc [Internet]. Elsevier B.V.; 2014;74:20-32. Available from: http://dx.doi.org/10.1016/j.vibspec.2014.07.001.

32. Joseph J, Jemmis ED. Red-, blue-, or no-shift in hydrogen bonds: A unified explanation. J Am Chem Soc. 2007;129:4620-32.

33. Behera B, Das PK. Blue- and Red-Shifting Hydrogen Bonding: A Gas Phase FTIR and Ab Initio Study

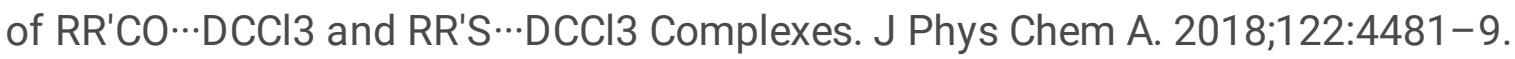

34. Tang Q, Chen Y, Gao H, Li Q, Xi Z, Zhao L, et al. Bio-Based Epoxy Resin from Epoxidized Soybean Oil. Yield Product: Soybean - Biomass; 2019.

35. Nash AM, Frankel EN. Limited extraction of soybeans with hexane. J Am Oil Chem Soc. 1986;63:244-6.

36. Sinha V, Patel MR, Patel JV. Pet waste management by chemical recycling: A review. J Polym Environ. 2010;18:8-25.

37. Giuliano F, Zagonel P, Peralta-Zamora LPR. Multivariate monitoring of soybean oil ethanolysis by FTIR. Talanta. 2004;63:1021-5.

38. 10.1016/j.indcrop.2011.10.036

Kim JR, Sharma S. The development and comparison of bio-thermoset plastics from epoxidized plant oils. Ind Crops Prod [Internet]. Elsevier B.V.; 2012;36:485-99. Available from: http://dx.doi.org/10.1016/j.indcrop.2011.10.036.

39. Awaja F, Pavel D. Recycling of PET. Eur Polym J. 2005;41:1453-77.

40. Karayannidis GP, Nikolaidis AK, Sideridou ID, Bikiaris DN, Achilias DS. Chemical recycling of PET by glycolysis: Polymerization and characterization of the dimethacrylated glycolysate. Macromol Mater Eng. 2006;291:1338-47.

41. Variola F. Atomic force microscopy in biomaterials surface science. Phys Chem Chem Phys Royal Society of Chemistry. 2015;17:2950-9. 
42. Reynaud C, Sommer F, Quet C, El Bounia N, Duc TM. Quantitative determination of Young's modulus on a biphase polymer system using atomic force microscopy. Surf Interface Anal. 2000;30:185-9.

43. Mashiur. Degradation of Polyesters in Medical Applications. Polyester. Intech; 2012. p. 100-32.

44. Yan M, Huang Y, Lu M, Lin FY, Hernández NB, Cochran EW. Gel Point Suppression in RAFT Polymerization of Pure Acrylic Cross-Linker Derived from Soybean Oil. Biomacromolecules. 2016;17:2701-9.

45. Lligadas G, Ronda JC, Galià M, Cádiz V. Renewable polymeric materials from vegetable oils: A perspective. Mater Today. 2013;16:337-43.

46. Lanser AC, List GR, Holloway RK, Mounts TL. FTIR estimation of free fatty acid content in crude oils extracted from damaged soybeans. J Am Oil Chem Soc. 1991;68:448-9.

\section{Figures}
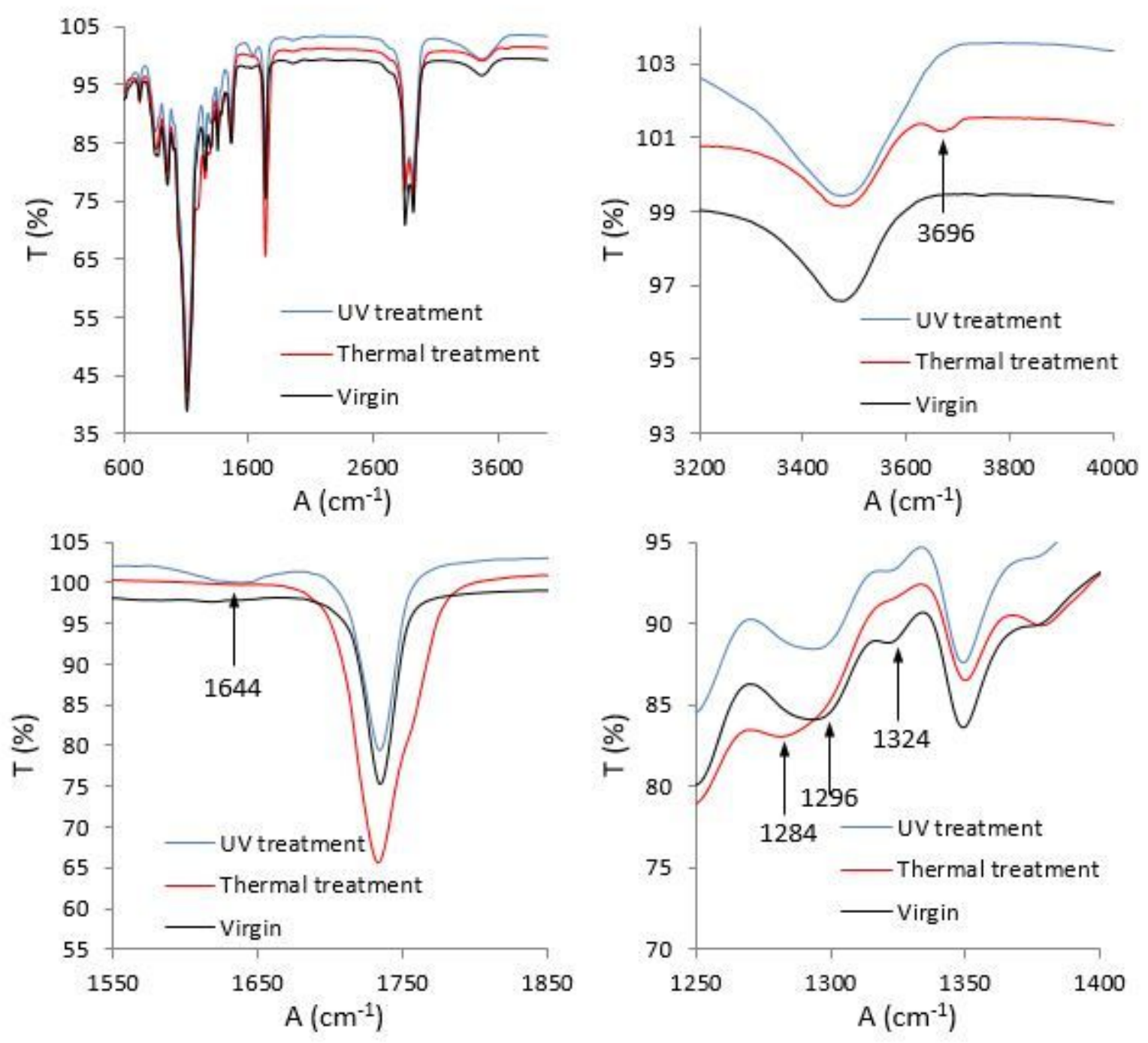

Figure 1 
Infrared spectra of virgin (control), UV exposed (UV treatment) and heated (thermal treatment) SFSB oils. (A) Full FTIR of original and treated oils; (B) Resolved spectral region from 3200-4000 cm-1; (C) Resolved spectral region from 1550-1850 cm-1; (D) Resolved spectral region from1250-1400 cm-1; UV treatment was irradiation $(254 \mathrm{~nm})$; thermal treatment at $100 \mathrm{oC}$ for 10 days, both under ambient atmospheric conditions.

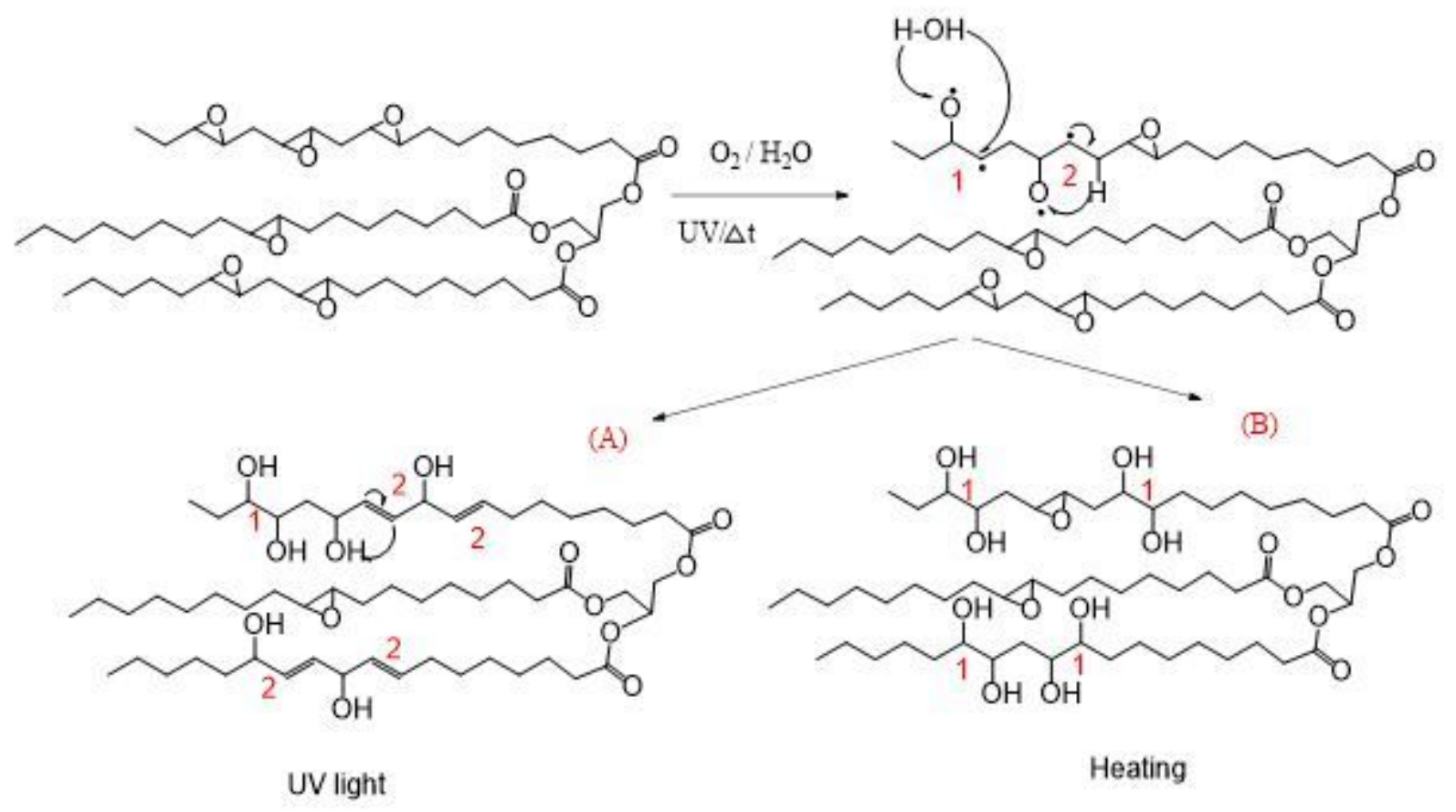

Figure 2

Scheme for modifications of epoxide soybean spin finish oil samples under (A) UV light irradiation (254 $\mathrm{nm})$ and $(\mathrm{B})$ heating $(100 \mathrm{oC})$ for 10 days. 

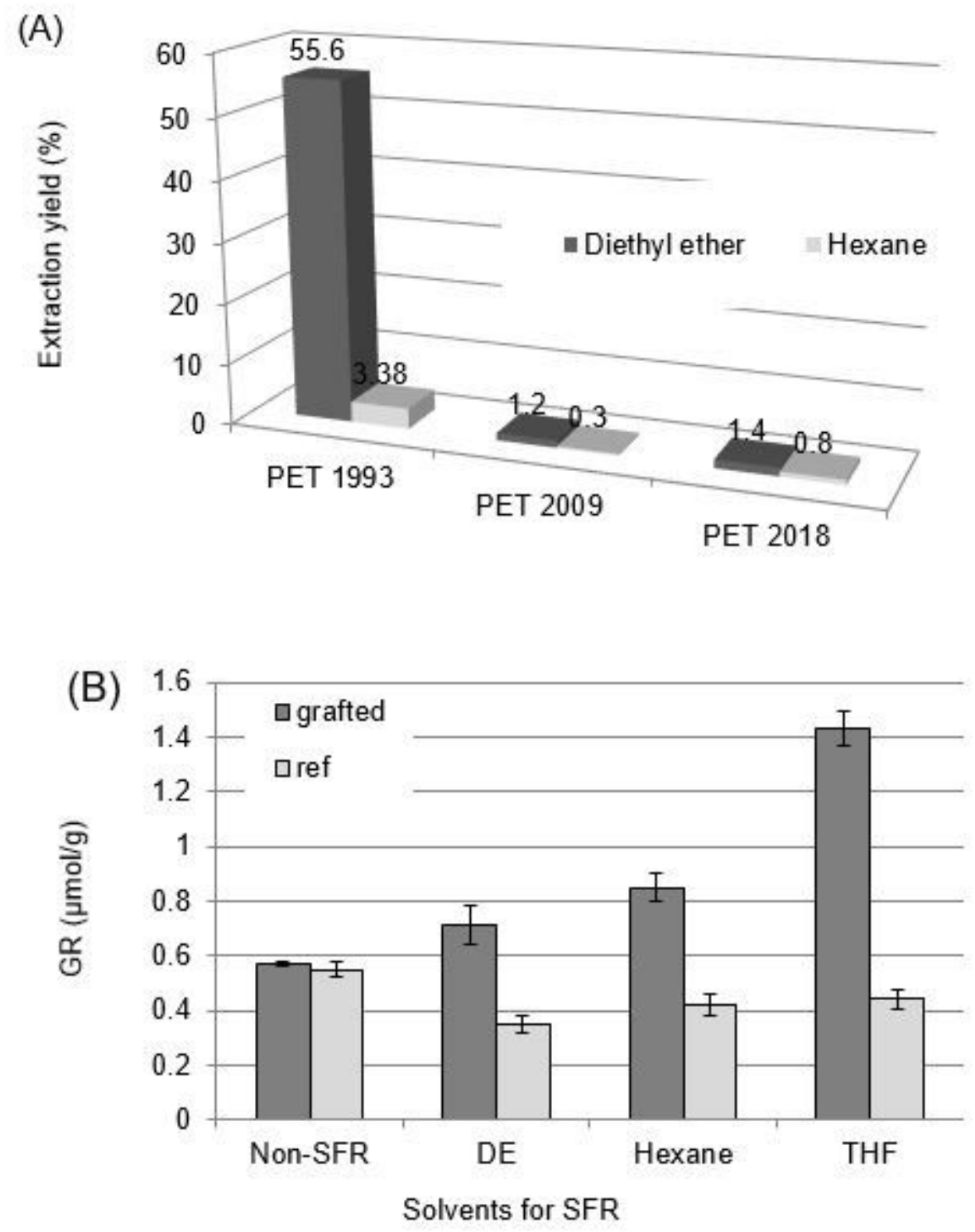

Figure 3

(A) SF oil extraction yields from PET ligaments of different storage times (i.e., 1993, 2009 and 2018) using diethyl ether and n-hexane; (B) SFR solvent effects on the PNaSS GR on PET2009 ligament (Ref: virgin $\mathrm{PET}$ fabric-non PNaSS grafting); $n=3, p<0.05$ 

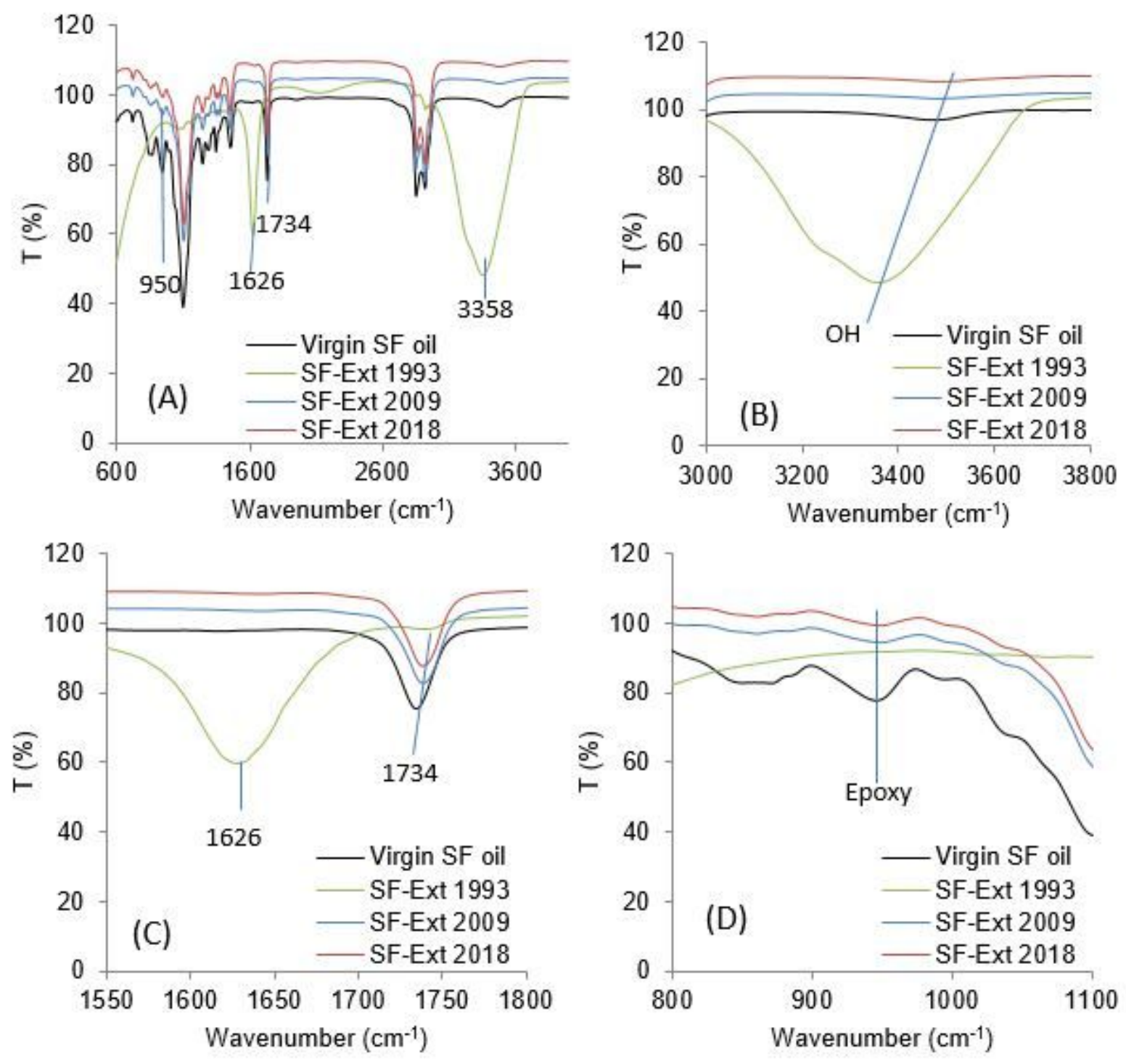

\section{Figure 4}

IR spectra of Soxhlet extracted oils from stored PET fabrics PET1993, 2009, 2018: (A) Overall spectra of spin-finish (SF) oil, extracted oil from PET $(1993,2009,2018)$ samples, respectively, (B) regional spectra from 3800-3000 cm-1, (C) regional spectra from1800-1550 cm-1, (D) regional spectra from 1100-800 cm1 

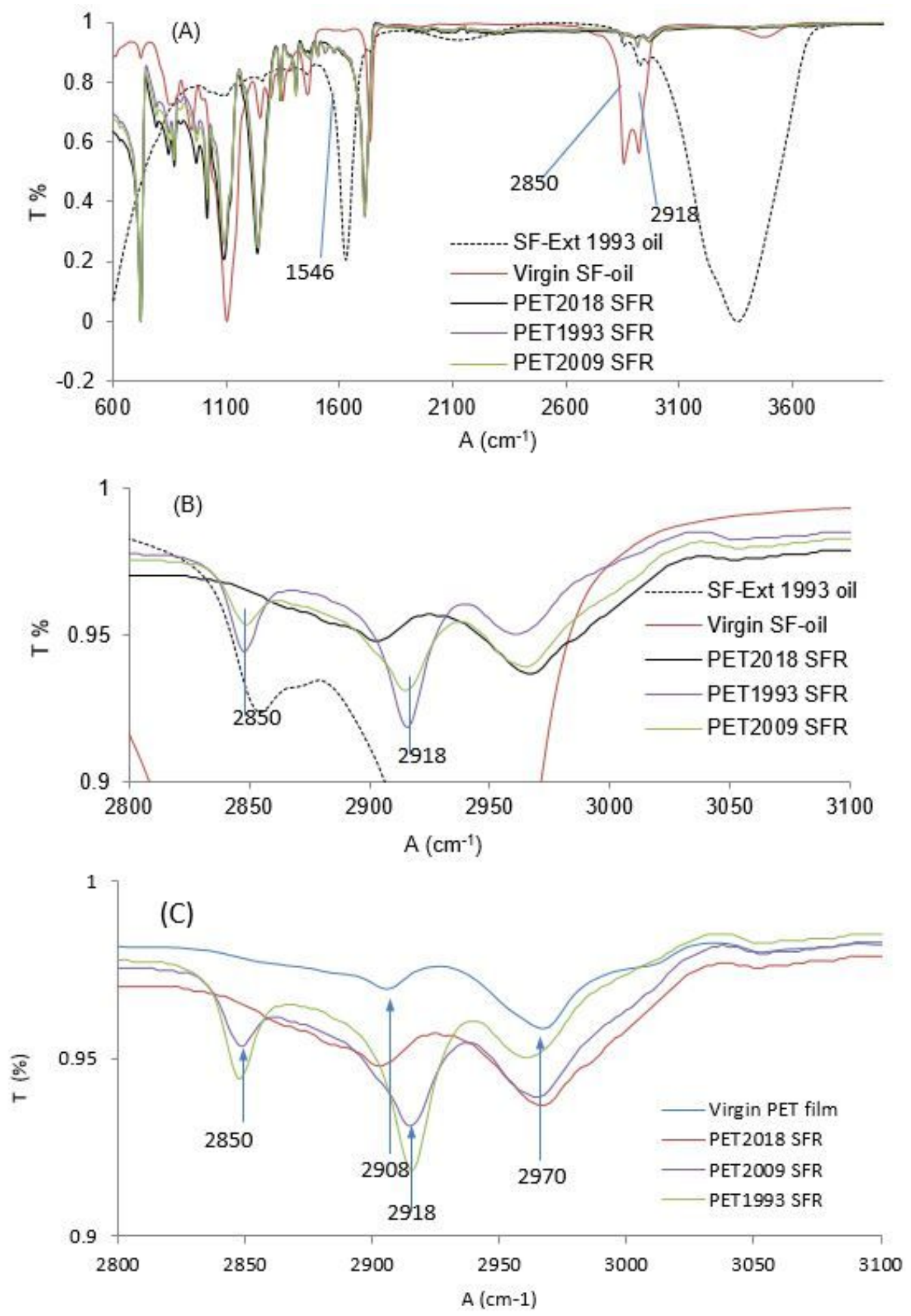

\section{Figure 5}

IR spectra of SFR PET fabrics (from 2018, 2009, and 1993) compared to virgin SF oil (non-degradation) and SF-Ext oil (degraded oil extracted from PET1993 fiber): (A) Overall spectra of spin-finish oil (virgin and modified extracted oil from ligament 1993) and spin finish removal fabrics, (B) regional spectra from A, shown from 2800 to $3100 \mathrm{~cm}-1$, and (C) Spectra of virgin PET film as a reference for spectral changes from spin finish removal from PET ligaments (regional spectra from 2800 to $3100 \mathrm{~cm}-1$ ). 


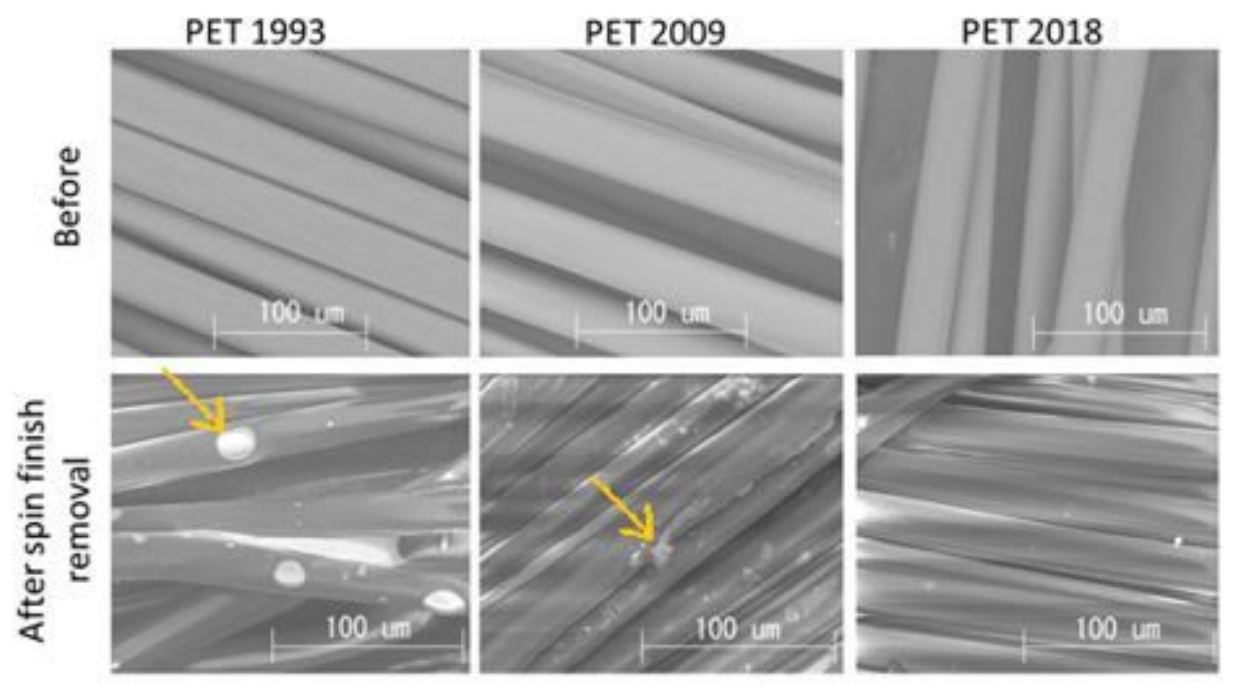

Figure 6

SEM images of PET fiber surfaces before and after Spin Finish Removal (SFR) under diethyl ether extraction; Yellow arrows indicate oil droplets or contaminants remaining on PET surfaces after SFR. Scale $=100 \mu \mathrm{m}$ 

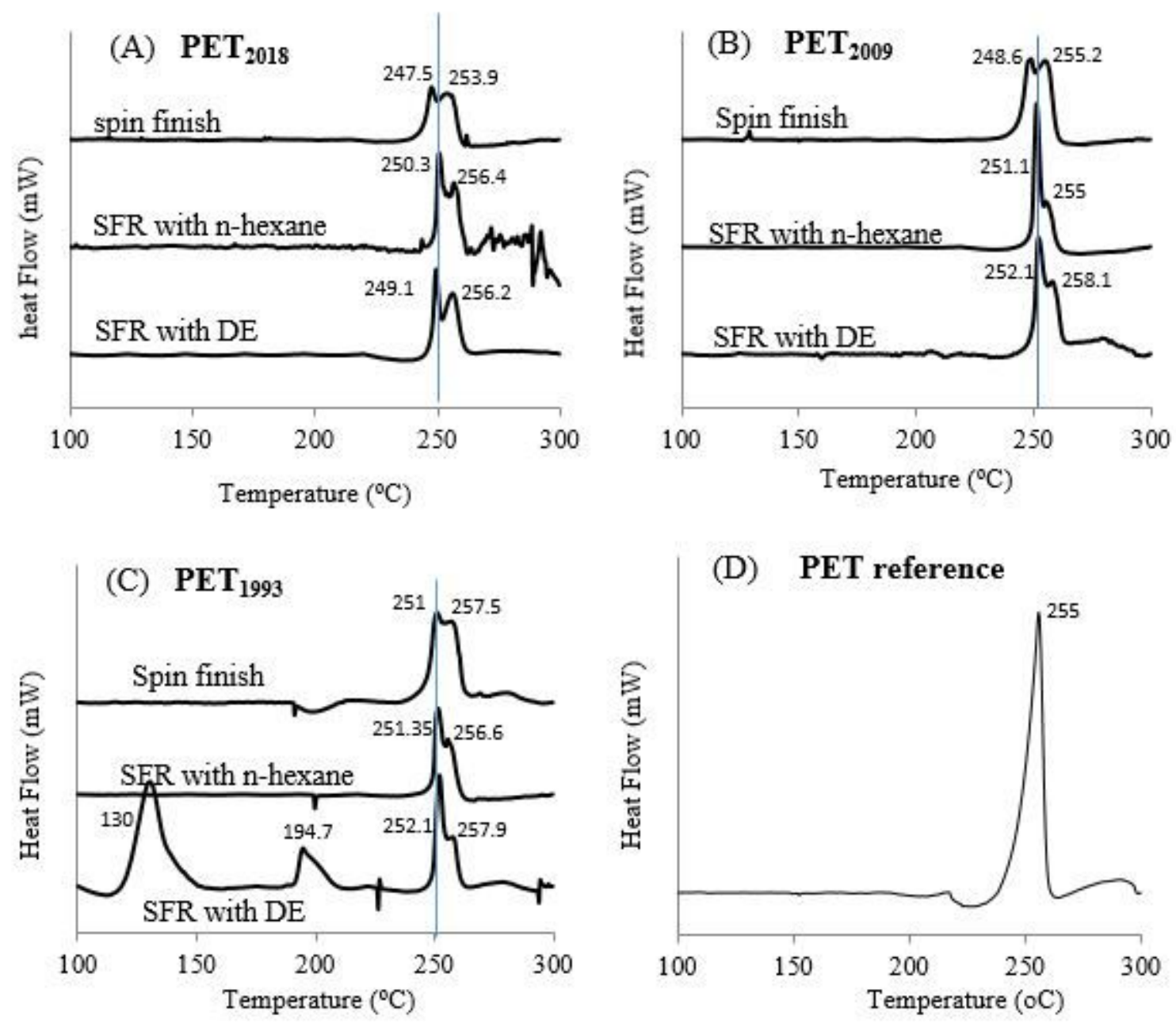

Figure 7

DSC first thermal analysis scan for PET fibers sourced from 1993, 2009, and 2018 before and after spin finish removal (SFR) with n-hexane and diethyl ether (DE): (A) PET2018, (B) PET2009, (C) PET1993, and (D) PET reference film $(n=3)$. 

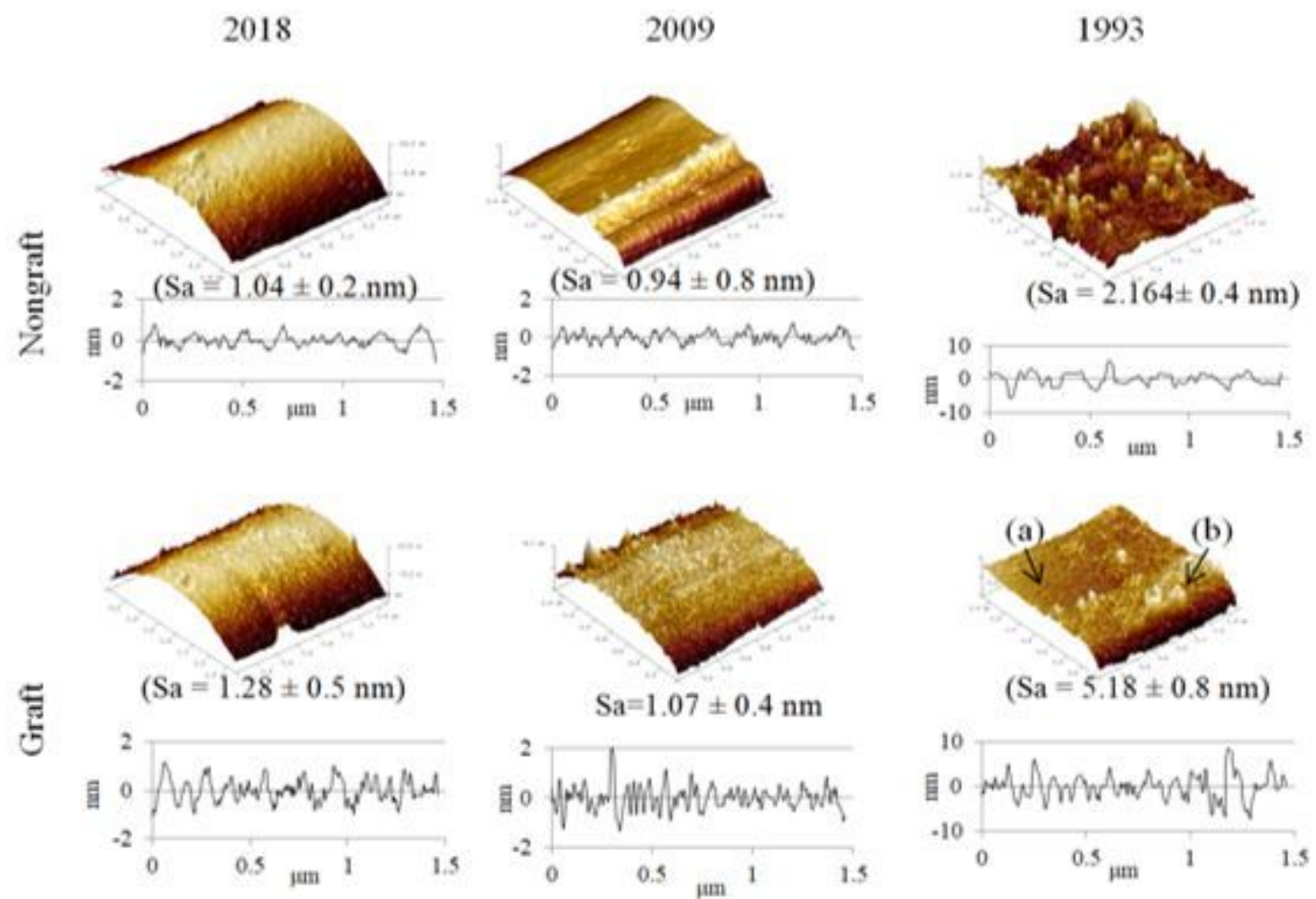

\section{Figure 8}

AFM imaging of PET fiber topography and roughness for fiber surfaces treated by SFR and PNaSS grafting protocols after different aging times shown at top of each column; Grafting conditions: PET samples were subject to SFR and then PNaSS functionalization protocols of ozonation for $10 \mathrm{~min}$ at $30 \mathrm{oC}$ and grafting for $1 \mathrm{~h}$ at $45 \mathrm{oC}$. AFM scan area: $1.5 \mu \mathrm{m} \times 1.5 \mu \mathrm{m}(0.5 \mathrm{~Hz})$ in air at $25 \mathrm{oC}(\mathrm{n}=3)$.
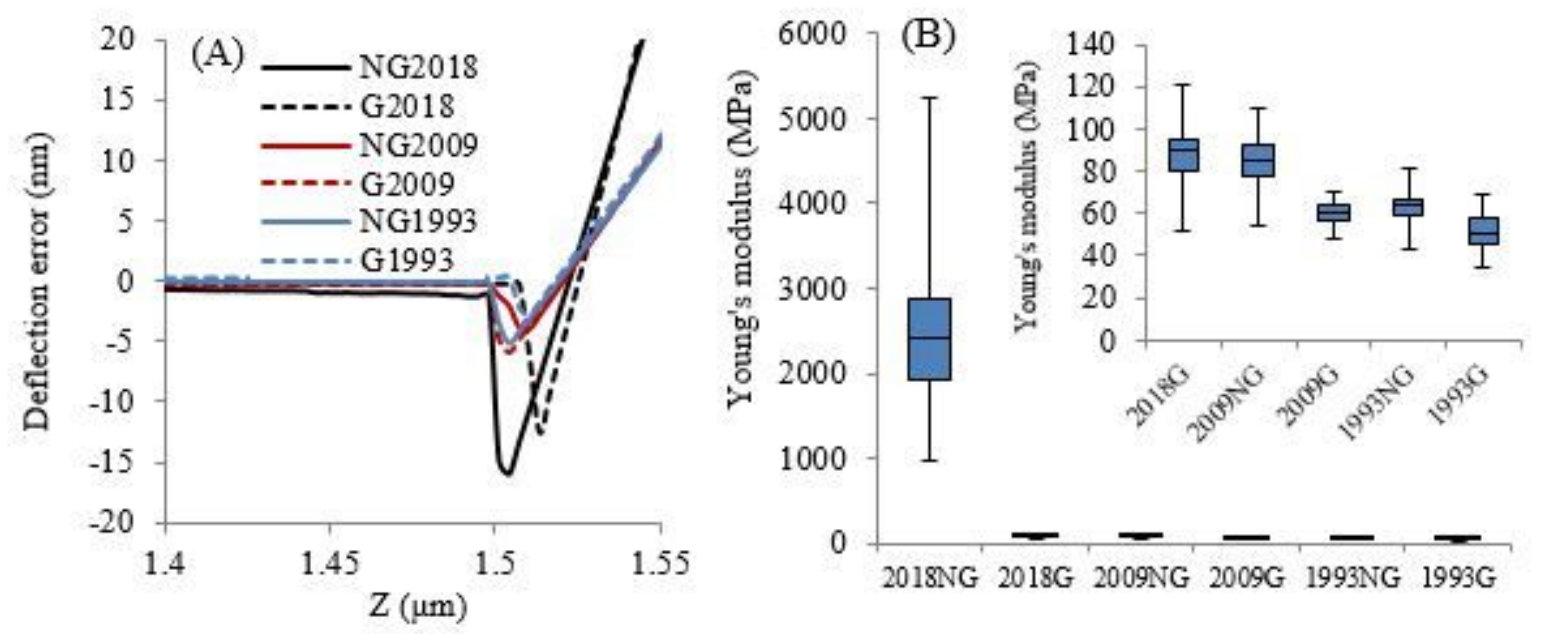

Figure 9 
(A) AFM force curve, and (B) Box plot of fiber surface Young's modulus measurement by Force Volume in air (25oC) on virgin and surface-pretreated, polymer-graft functionalized PET2018, 2009, 1993. "NG" for no grafting, and "G" for PNaSS grafting.

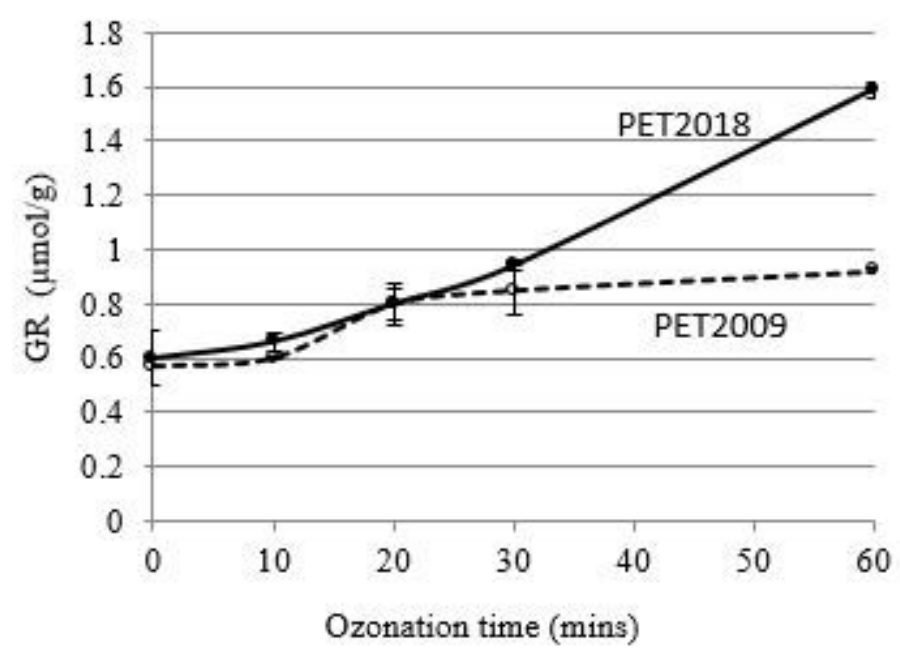

Figure 10

PNaSS GR for PET2009 and PET2018 fabrics versus ozonation times. Samples SFR used diethyl ether. Ozonation was performed at $30 \mathrm{oC}$, and PNaSS grafting polymerization at $45 \mathrm{oC}$ over time for up to $1 \mathrm{~h}$ (n $=5)$. TB assay was used to determine GR. 

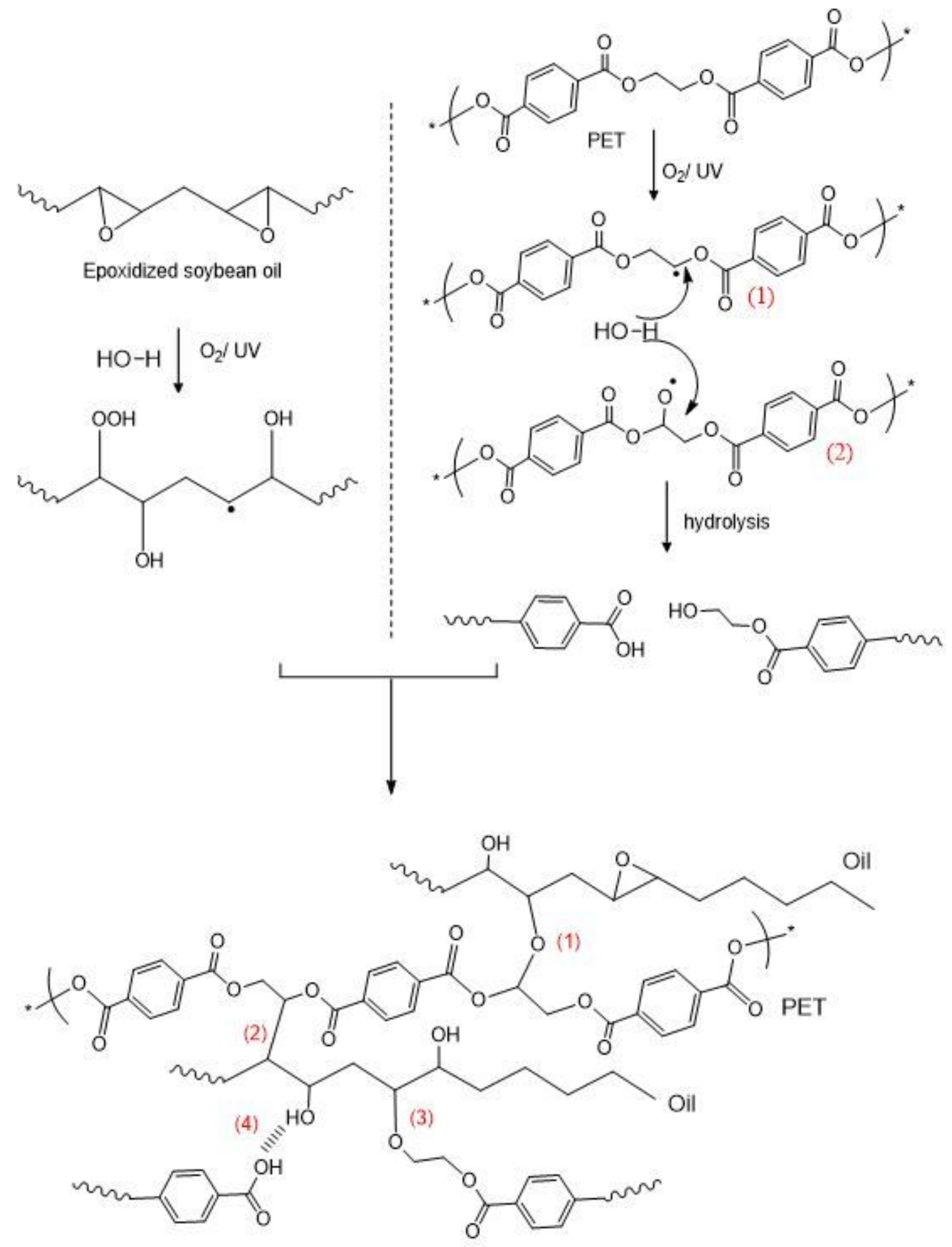

\section{Figure 11}

Schematic for UV/O2 effects on SF-oil and PET interactions: UV/O2, temperature, and humidity effects on intermolecular crosslinking and hydrogen bond generation between oil and PET, and oil-degraded PET fractions, and hydrogen bonds

\section{Supplementary Files}


This is a list of supplementary files associated with this preprint. Click to download.

- SupportingInformation.docx 